Check for updates

Cite this: Chem. Sci., 2019, 10, 3738

๑ All publication charges for this article have been paid for by the Royal Society of Chemistry

Received 7th December 2018 Accepted 21st February 2019

DOI: $10.1039 / c 8 s c 05473 h$

rsc.li/chemical-science

\section{Thorium- and uranium-azide reductions: a transient dithorium-nitride versus isolable diuranium-nitrides $\uparrow$}

\author{
Jingzhen Du, (D) $\ddagger^{\mathrm{a}}$ David M. King, $\dot{t}^{\mathrm{b}}$ Lucile Chatelain, ${ }^{\mathrm{a}}$ Erli Lu, ${ }^{a}$ Floriana Tuna, (D) ${ }^{a}$ \\ Eric J. L. Mclnnes, ${ }^{a}$ Ashley J. Wooles, ${ }^{a}$ Laurent Maron (iD ${ }^{* c}$ and Stephen T. Liddle (DD *a
}

Molecular uranium-nitrides are now well known, but there are no isolable molecular thorium-nitrides outside of cryogenic matrix isolation experiments. We report that treatment of $\left[M\left(\operatorname{Tren}^{\mathrm{DMBS}}\right)(\mathrm{I})\right](\mathrm{M}=\mathrm{U}, 1$;

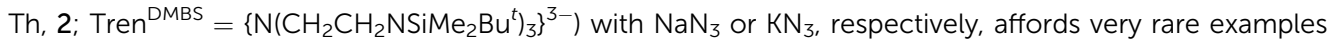
of actinide molecular square and triangle complexes $\left[\left\{M\left(\operatorname{Tren}^{\mathrm{DMBS}}\right)\left(\mu-\mathrm{N}_{3}\right)\right\}_{n}\right](M=U, n=4,3 ;$ Th, $n=3$, 4). Chemical reduction of 3 produces $\left[\left\{U\left(\operatorname{Tren}^{\mathrm{DMBS}}\right)\right\}_{2}(\mu-\mathrm{N})\right]\left[K(T H F)_{6}\right](5)$ and $\left[\left\{U\left(\operatorname{Tren}^{\mathrm{DMBS}}\right)\right\}_{2}(\mu-N)\right](6)$, whereas photolysis produces exclusively 6 . Complexes 5 and 6 can be reversibly inter-converted by oxidation and reduction, respectively, showing that these UNU cores are robust with no evidence for any $\mathrm{C}-\mathrm{H}$ bond activations being observed. In contrast, reductions of 4 in arene or ethereal solvents gives $\left[\left\{\mathrm{Th}\left(\operatorname{Tren}^{\mathrm{DMBS}}\right)\right\}_{2}(\mu-\mathrm{NH})\right]$ (7) or $\left[\left\{\mathrm{Th}\left(\operatorname{Tren}^{\mathrm{DMBS}}\right)\right\}\left\{\mathrm{Th}\left(\mathrm{N}\left[\mathrm{CH}_{2} \mathrm{CH}_{2} \mathrm{NSiMe}_{2} \mathrm{Bu}^{t}\right]_{2} \mathrm{CH}_{2} \mathrm{CH}_{2} \mathrm{NSi}\left[\mu-\mathrm{CH}_{2}\right] \mathrm{MeBu}^{t}\right)\right\}(\mu-\right.$ $\mathrm{NH})]\left[K(D M E)_{4}\right](8)$, respectively, providing evidence unprecedented outside of matrix isolation for a transient dithorium-nitride. This suggests that thorium-nitrides are intrinsically much more reactive than uranium-nitrides, since they consistently activate $\mathrm{C}-\mathrm{H}$ bonds to form rare examples of $\mathrm{Th}-\mathrm{N}(\mathrm{H})-\mathrm{Th}$ linkages with alkyl by-products. The conversion here of a bridging thorium(IV)-nitride to imido-alkyl combination by 1,2 -addition parallels the reactivity of transient terminal uranium(iv)-nitrides, but contrasts to terminal uranium(vi)-nitrides that produce alkyl-amides by 1,1-insertion, suggesting a systematic general pattern of $\mathrm{C}-\mathrm{H}$ activation chemistry for metal(Iv)- vs. metal(vi)-nitrides. Surprisingly, computational studies reveal a $\sigma>\pi$ energy ordering for all these bridging nitride bonds, a phenomenon for actinides only observed before in terminal uranium nitrides and uranyl with very short $\mathrm{U}-\mathrm{N}$ or $\mathrm{U}-\mathrm{O}$ distances.

\section{Introduction}

In recent years there have been major developments in uraniumligand multiple bonding, ${ }^{1}$ and arguably none more so than $\mathrm{U}-\mathrm{N}$ multiple bonds. ${ }^{2}$ For example, significant advances include bis-, tris-, and tetrakis-imido complexes, ${ }^{3-5}$ two parent imido complexes, ${ }^{6}$ reductive cleavage and functionalisation of $\mathrm{N}_{2},{ }^{7}$ terminal $\mathrm{N}_{2}$ and NO complexes, ${ }^{8}$ and the emergence of isolable uranium-nitrides. ${ }^{\mathbf{9 - 1 1}}$ Such studies are motivated by a desire to prepare actinide congeners of linkages known for decades in the d-block in order to better understand covalency in actinide

${ }^{a}$ School of Chemistry, The University of Manchester, Oxford Road, Manchester, M13 9PL, UK. E-mail: steve.liddle@manchester.ac.uk

${ }^{b}$ School of Chemistry, The University of Nottingham, University Park, Nottingham, NG7 $2 R D, U K$

${ }^{c}$ LPCNO, CNRS, INSA, Université Paul Sabatier, 135 Avenue de Rangueil, Toulouse 31077, France. E-mail: laurent.maron@irsamc.ups-tlse.fr

$\dagger$ Electronic supplementary information (ESI) available: Full experimental and computational details. CCDC 1868610-1868615. For ESI and crystallographic data in CIF or other electronic format see DOI: $10.1039 / \mathrm{c} 8 \mathrm{sc} 05473 \mathrm{~h}$

\$ These authors contributed equally to this work. chemical bonding and to map out intrinsic reactivity trends; ${ }^{12}$ however, equivalent metal-ligand bonds need to be compared with different actinide elements to elucidate periodic trends. In that regard, thorium analogues demand attention, but there are few mono-imido and bis-imido derivatives, and no parent imidos. ${ }^{13}$ There are no isolable molecular thorium-nitrides to date, but under cryogenic matrix isolation conditions elegant species such as ThN, $\mathrm{F}_{3}$ ThN, NThN, Th(N)$)_{2}$ Th, and NThO have been reported. ${ }^{\mathbf{1 4}} \mathrm{A}$ transient zero-valent thorium synthon produced a Th$\mathrm{NH}_{2}$ linkage from $\mathrm{N}_{2},{ }^{15}$ but it is not known whether this transformation involves a transient thorium-nitride or if a conventional biomimetic-type $\left(\mathrm{H}^{+} / \mathrm{e}^{-}\right)$pathway is followed.

Building on our prior work on terminal uranium-nitrides, ${ }^{\mathbf{1 1}}$ we have reported complexes containing parent terminal $\mathrm{U}=\mathrm{EH}$ $(\mathrm{E}=\mathrm{N}, \mathrm{P}, \mathrm{As})$ and bridging $\mathrm{UP}(\mathrm{H}) \mathrm{U}$, UPU, and $\mathrm{UAsK}_{2}$ linkages. ${ }^{6 a, 16 a, b, e}$ For thorium, we have prepared complexes exhibiting parent terminal $\mathrm{Th}=\mathrm{PH}$, and bridging $\operatorname{ThP}(\mathrm{H}) \mathrm{Th}$, $\operatorname{ThAs}(\mathrm{H})$ Th, ThAs(H)K, ThPTh and ThAsTh units. ${ }^{16 c, d}$ We previously observed that bridging ThPTh and ThAsTh linkages are stable and isolable in triamidoamine derivatives, but conversely UPU and $\mathrm{UAsK}_{2}$ linkages are highly unstable and readily decompose. 
In contrast, most bridging UNU units seem to be relatively stable, ${ }^{\mathbf{1 0 b}, f_{,}, j, \boldsymbol{k}}$ though none are known with triamidoamine ancillary ligands. Thus, how ThNTh units would fit into these stability patterns is unknown and cannot be predicted with any certainty. So, we have initially sought to prepare dithoriumnitrides, as well as diuranium analogues for comparison, supported by triamidoamines.

Here, we report the synthesis and characterisation of two triamidoamine uranium- and thorium-azides. Despite marginal differences in the covalent radii of these metals, the uranium complex is a rare example of an actinide molecular square whereas the thorium analogue is a molecular triangle. Reduction of the uranium-azide complex generates diuraniumnitrides, with two charge states of a UNU core being accessible, and interchangeable, with no evidence of $\mathrm{C}-\mathrm{H}$ activation chemistry even under photolytic conditions. However, a ThNTh complex could not be isolated. Instead, the isolation of two ThN(H)Th complexes, which is an unprecedented linkage in thorium chemistry and rare in f-block chemistry generally, ${ }^{7 c, d}$ suggests that a dithorium-nitride complex is transiently formed but activates any available $\mathrm{C}-\mathrm{H}$ bonds, be they part of arene solvent or in the absence of arenes the triamidoamine ligand. The ThNTh unit therefore appears to be highly reactive in a triamidoamine ligand environment, and its instability contrasts to ThPTh and ThAsTh congeners and UNU analogues and also suggests a systematic pattern of metal oxidation statedependent $\mathrm{C}-\mathrm{H}$ activation reactivity for actinide-nitrides. Surprisingly, computational studies reveal a $\sigma>\pi$ energy ordering for the bridging nitride linkages in this study, a phenomenon so far only found in terminal uranium-nitrides and uranyl complexes with very short $\mathrm{U}-\mathrm{N} /-\mathrm{O}$ distances.

\section{Results and discussion}

\section{Preparation of uranium- and thorium-azide complexes}

In order to prepare $\mathrm{MNM}$ linkages we pursued a $\mathrm{M}-\mathrm{N}_{3}$ reduction approach using the Tren ${ }^{\text {DMBS }}\left\{\mathrm{N}\left(\mathrm{CH}_{2} \mathrm{CH}_{2} \mathrm{NSiMe}_{2} \mathrm{Bu}^{t}\right)_{3}\right\}^{3-}$ ligand as this was anticipated to be sterically open enough to allow any nitrides to bridge, whereas the bulkier Tren ${ }^{\text {TIPS }}\left\{\mathrm{N}\left(\mathrm{CH}_{2} \mathrm{CH}_{2}\right.\right.$ $\left.\left.\mathrm{NSiPr}_{3}^{\mathrm{i}}\right)_{3}\right\}^{3-}$ variant stabilises ThPTh and ThAsTh linkages but terminal UN for uranium. Accordingly, treatment of $\left[\mathrm{M}\left(\operatorname{Tren}^{\mathrm{DMBS}}\right)(\mathrm{I})\right](\mathrm{M}=\mathrm{U}, \mathbf{1} ; \mathrm{Th}, 2)^{17}$ with excess $\mathrm{NaN}_{3}$ or $\mathrm{KN}_{3}$ affords $\left[\left\{\mathrm{M}\left(\text { Tren }^{\text {DMBS }}\right)\left(\mu-\mathrm{N}_{3}\right)\right\}_{n}\right](\mathrm{M}=\mathrm{U}, n=4,3$; Th, $n=3,4)$ as green-yellow and colourless crystalline solids after work-up in isolated yields of 35 and $86 \%$, respectively, Schemes 1 and $2 .^{18}$ The combined characterisation data support the formulations of 3 and 4, in particular the ATR-IR spectra of 3 and 4 both exhibit strong absorptions at $2131 \mathrm{~cm}^{-1}$, which is characteristic of actinide-bound bridging-azide ligands. ${ }^{\mathbf{1 0 b}, \boldsymbol{c}, \mathbf{1 9}}$ The magnetic moment of 3, Fig. $1,{ }^{18}$ in the solid-state at $298 \mathrm{~K}$ is $5.52 \mu_{\mathrm{B}}$ per molecule decreasing smoothly to $0.78 \mu_{\mathrm{B}}$ at $2 \mathrm{~K}$ (3.29 and $0.41 \mu_{\mathrm{B}}$ per uranium ion in 3 , respectively) and tending to zero as expected for a tetrametallic $\mathrm{U}^{\mathrm{IV}}$ complex, since $\mathrm{U}^{\mathrm{IV}}$ usually has a magnetic singlet ground state at low temperature.,20

In order to confirm the formulations of 3 and 4 we determined their solid-state structures, Fig. 2a and 3a. Surprisingly, although 1 and 2, and chloride analogues, are monomers, 3 and
4 are tetrameric and trimeric in the solid-state. Such molecular squares and triangles ${ }^{21}$ are relatively rare motifs in actinide chemistry, ${ }^{10 b, c, 22}$ since polymeric formulations tend to dominate $^{\mathbf{1 9 f}}$ as there is not usually a strong orbitally-driven geometric preference for $\mathrm{M}-\mathrm{L}$ angles that generate squares or triangles. However, it would appear that when the $C_{3 \mathrm{v}}$ symmetry of Tren $^{\text {DMBS }}$ is lowered to $C_{\mathrm{s}}$ the cleft that opens up allows two azides to enter the coordination sphere of uranium in 3 at an approximate right angle $\left(\sim 85^{\circ}\right)$ whereas for the larger thorium in 4 the azides approach at a slightly more acute N-Th-N angle $\left(\sim 79^{\circ}\right)$, which seems to be enough to switch from tetramer to trimer. It would seem that the $\mathrm{N}-\mathrm{Th}-\mathrm{N}$ angle can close at the larger metal without as much inter-azide clashing due to longer Th-N bonds placing the azides further apart from one another, which accounts for the aggregation states of 3 and 4 . The $\mathrm{U}-$ and Th- $\mathrm{N}_{\text {azide }}$ distances in $\mathbf{3}$ and $\mathbf{4}$ are longer than in terminal azide complexes, ${ }^{19}$ and we note that they are longer when trans to a Tren $^{\text {DMBS }}$ amide centre $(3,2.540(5) ; 4,2.609(8) \AA$ av.) than amine centre $(3,2.425(5) ; 4,2.478(7) \AA$ av. $)$, possibly implying a trans-influence. All other bond lengths are within normal ranges and do not suggest any strong activation of the azides.

\section{Uranium-azide reductions and characterisation of nitride products}

With 3 and 4 in-hand we investigated their reduction chemistries. The reaction of 3 with $\mathrm{KC}_{8}$ always produces the diuranium(Iv/Iv)-nitride $\left[\left\{\mathrm{U}\left(\text { Tren }^{\mathrm{DMBS}}\right)\right\}_{2}(\mu-\mathrm{N})\right]\left[\mathrm{K}(\mathrm{THF})_{6}\right](5)$ and the mixed-valence diuranium(Iv/v)-nitride $\left[\left\{\mathrm{U}\left(\operatorname{Tren}^{\mathrm{DMBS}}\right)\right\}_{2}(\mu-\mathrm{N})\right](6)$ in $\sim 42 \%$ overall yield (total yield by uranium content, $28 \% 5$ and $14 \% 6$ estimated from integration of ${ }^{1} \mathrm{H}$ NMR data), with concomitant elimination of $\mathrm{N}_{2}$ and $\mathrm{KN}_{3} \cdot{ }^{18}$ The ratio of $5: 6$ varies from $77: 23$ to $50: 50$ as the $\mathrm{KC}_{8}$ ratio is varied from 5 to 3 equivalents but is independent of the solvent used (benzene, toluene, THF, DME). Other $\mathrm{KC}_{8}$ ratios gave intractable product mixtures. Complexes 5 and $\mathbf{6}$ can be separated by fractional crystallisation, however we find that $\mathbf{6}$ can be cleanly prepared in $45 \%$ isolated crystalline yield by photolysis of 3 with a $125 \mathrm{~W}$ Hg-lamp for 7 hours. Gratifyingly, 6, or a known mixture of 5 and 6 , can be reduced with $\mathrm{KC}_{8}$ to give solely 5 , and 5 or a known mixture of 5 and 6 can be oxidised with $\mathrm{AgBPh}_{4}$ to give exclusively $\mathbf{6}$, Scheme 1 . Interestingly, $\mathbf{5}$ and $\mathbf{6}$ are always formed in the respective reduction and oxidation reactions, irrespective of the amounts of $\mathrm{KC}_{8}$ (2-8 equiv.) and $\mathrm{AgBPh}_{4}$ (2-3 equiv.) used, and we found no evidence for further reductions or oxidations, respectively.

As expected, the characterisation data for $\mathbf{5}$ and $\mathbf{6}$ are distinct, reflecting their $\mathrm{U}^{\mathrm{IV}} / \mathrm{U}^{\mathrm{IV}}$ and $\mathrm{U}^{\mathrm{IV}} / \mathrm{U}^{\mathrm{V}}$ formulations, respectively. The ${ }^{1} \mathrm{H}$ NMR spectra of 5 and $\mathbf{6}$ span the ranges +96 to -34 and +25 to $-13 \mathrm{ppm}$, respectively, reflecting their $5 \mathrm{f}^{2 / 2} v s$. $5 \mathrm{f}^{2 / 1}$ natures. The solution Evans method (298 K) gives magnetic moments of 4.0 and $3.5 \mu_{\mathrm{B}}$ per molecule of 5 and $\mathbf{6}$, whereas the solid-state magnetic moments, Fig. $1,{ }^{18}$ are 4.70 and $3.39 \mu_{\mathrm{B}}$, respectively. These values decrease to 1.00 and $1.07 \mu_{\mathrm{B}}$ at $2 \mathrm{~K}$, respectively. For 5 the respective values per uranium ion are $3.39(298 \mathrm{k})$ and $0.74 \mu_{\mathrm{B}}(2 \mathrm{~K})$, which per ion are slightly higher than the corresponding values for 3 reflecting their nitride and 


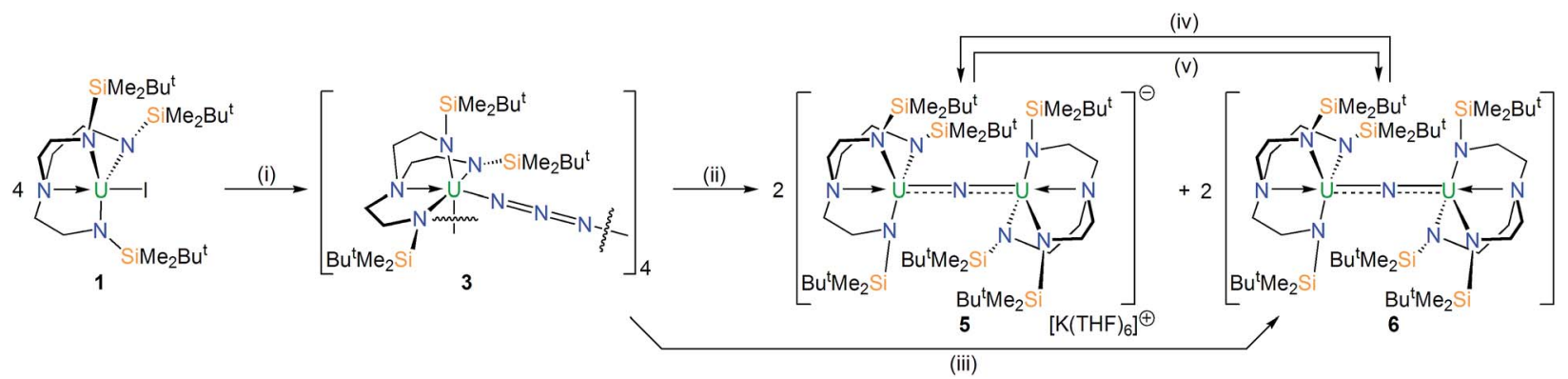

Scheme 1 Synthesis of 3, 5 and 6 from 1. Reagents and conditions: (i) $4 \mathrm{NaN}_{3}, \mathrm{THF},-4 \mathrm{Nal}$; (ii) $4 \mathrm{KC}_{8}, \mathrm{THF},-4 \mathrm{C}_{8},-2 \mathrm{KN}_{3},-2 \mathrm{~N}_{2}$; (iii) $h \nu, 125 \mathrm{~W} H \mathrm{Hg}$ lamp, $7 \mathrm{~h}$, toluene, $-5 \mathrm{~N}_{2} ;$ (iv) $\mathrm{KC}_{8}, \mathrm{THF},-\mathrm{C}_{8} ;(\mathrm{v}) \mathrm{AgBPh}_{4}$, toluene, $-\mathrm{KBPh}_{4},-\mathrm{Ag}^{\mathrm{O}},-6 \mathrm{THF}$.

azide formulations. ${ }^{16 b, 23}$ The data for 6 are consistent with its $\mathrm{U}^{\mathrm{IV}} / \mathrm{U}^{\mathrm{V}}$ combination, ${ }^{2,20}$ where the $\mathrm{U}^{\mathrm{V}}$ ion has a magnetic doublet ground state at all temperatures, and antiferromagnetic U-U coupling is suggested by a maximum at $\sim 60 \mathrm{~K}$ in the $\chi v s$. $T$ plot of $5 .{ }^{2,24,25}$ The presence of $\mathrm{U}^{\mathrm{V}}$ in 6 is unequivocally confirmed by EPR spectroscopy (S- and X-bands) at $5 \mathrm{~K}$, Fig. $4,{ }^{18}$ which reveals two similar sets of rhombic $g$ values with $g_{\text {eff }}=3.13,0.95,0.50$, and 2.70, 0.74, 0.43; these data reflect the presence of two conformational isomers in the solidstate structure of $\mathbf{6}$ due to positional disorder of three of the six $\mathrm{SiMe}_{2} \mathrm{Bu}^{t}$ groups, and we note that the effective $g$-values of spinorbit doubles are extremely sensitive to small changes in structure. ${ }^{26} \mathrm{An}$ electrochemical irreversible one-electron process at $E_{1 / 2}-1.4 \mathrm{~V}\left(v s .\left[\mathrm{Fc}(\mathrm{Cp})_{2}\right]^{0 /+1}\right)$ for the $\left[\mathrm{U}^{\mathrm{IV}} / \mathrm{U}^{\mathrm{V}}\right] /\left[\mathrm{U}^{\mathrm{IV}} / \mathrm{U}^{\mathrm{IV}}\right]^{-}$redox couple is found, Fig. 5 , which contrasts to 3 and $\mathbf{4}$ which do not exhibit any electrochemical events in the solvent-accessible window of 2.5 to $-3.0 \mathrm{~V}$. The chemical inter-conversion of 5 and 6 suggests the presence of robust UNU cores, as was found for $\left[\left\{\mathrm{U}\left(\mathrm{NBu}^{t}\left[3,5-\mathrm{Me}_{2} \mathrm{C}_{6} \mathrm{H}_{3}\right]\right)_{3}\right\}_{2}(\mu-\mathrm{N})\right]^{n}(n=+1,0,-1)$ which can exist in three charge states, ${ }^{\mathbf{1 0} f}$ but the irreversible electrochemical behaviour may reflect structural changes in the $\mathrm{U}=\mathrm{N}=\mathrm{U}$ angles of 5 compared to $\mathbf{6}$ (see below).

The solid-state structures of 5 and $\mathbf{6}$ were determined, Fig. $2 \mathrm{~b}$ and c, revealing structural differences reflecting their different oxidation state formulations. The anion component of $\mathbf{5}$ resides on a crystallographic 3-fold rotation axis and therefore the $\mathrm{U}-\mathrm{N}-\mathrm{U}$ and $\mathrm{N}_{\text {nitride }}-\mathrm{U}-\mathrm{N}_{\mathrm{amine}}$ angles are rigorously $180^{\circ}$, however in 6 the $\mathrm{U}-\mathrm{N}-\mathrm{U}$ angle is bent at $161.2(2)^{\circ}$. In 5 the U1/2-N nitride, amide, and amine distances are 2.0648(2), 2.343(3), and 2.733(5) $\AA$, respectively; these distances reflect the bridging nature of the

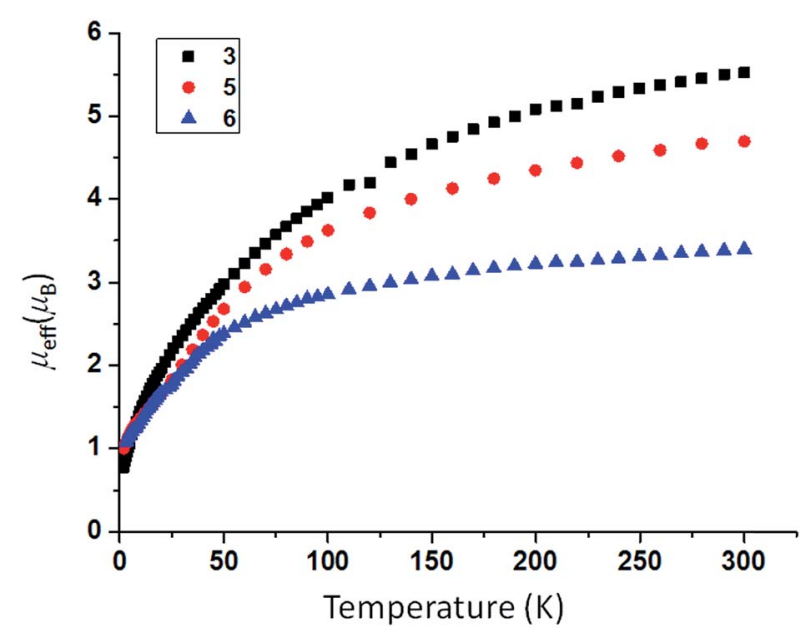

Fig. 1 Variable temperature SQUID magnetic moment data for 3 (black squares), 5 (red circles), and 6 (blue triangles) over the range 2$300 \mathrm{~K}$.

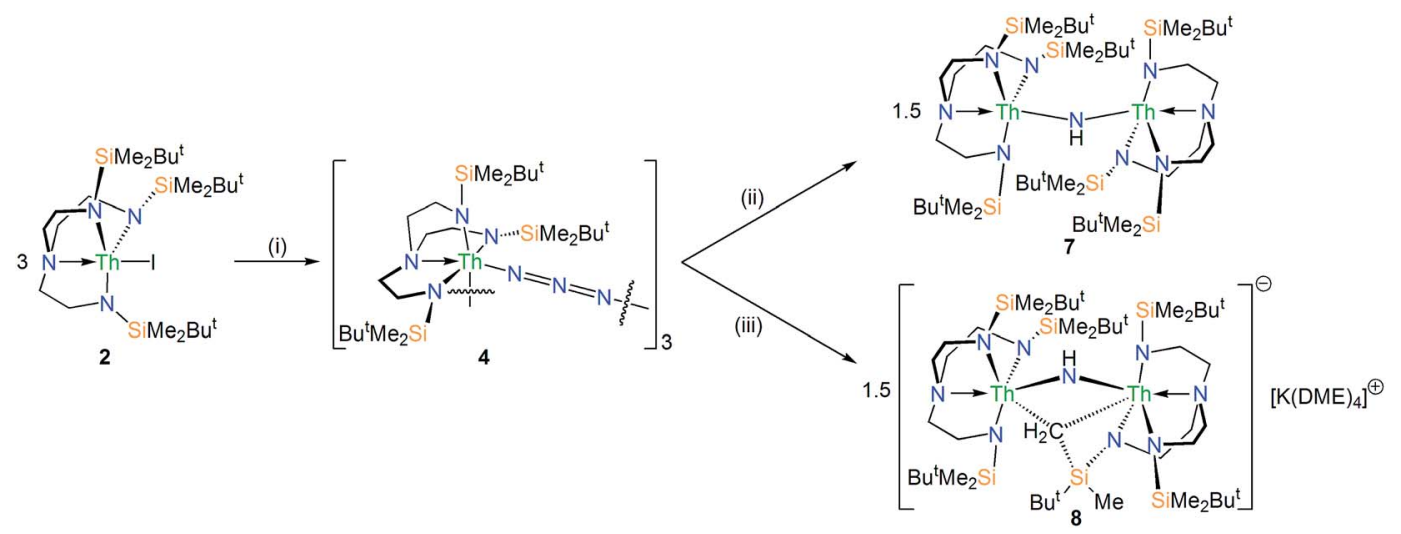

Scheme 2 Synthesis of 4,7 and 8 from 2. Reagents and conditions: (i) $3 K_{3}, T H F,-3 K$; (ii) $3 K C_{8}$, benzene or toluene, $-3 C_{8},-1.5 K N_{3},-1.5 N_{2}$, $-\mathrm{KCH}_{2} \mathrm{Ph}$ or $-\mathrm{KC}_{6} \mathrm{H}_{5}$; (iii) $3 \mathrm{KC}_{8}$, THF or DME, $-1.5 \mathrm{KN}_{3},-1.5 \mathrm{~N}_{2}$. 


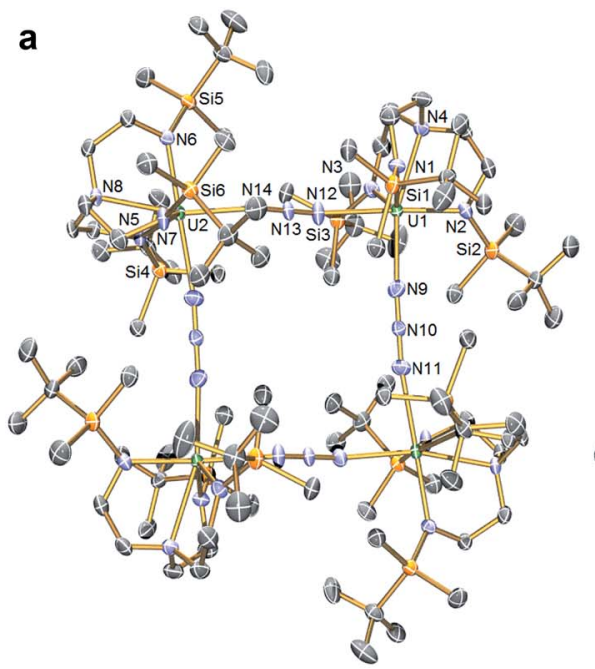

b

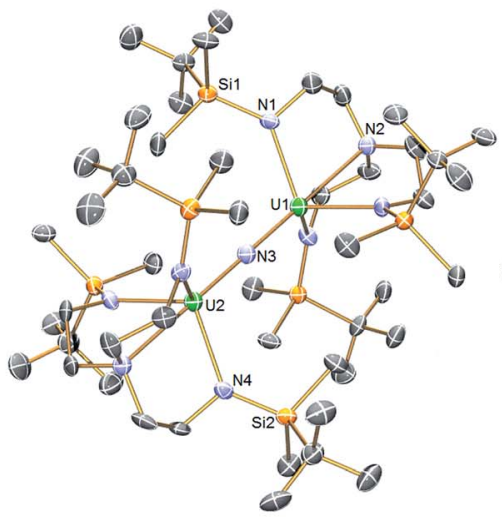

C

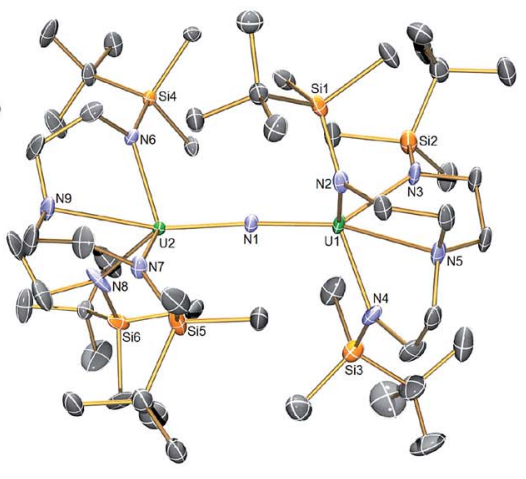

Fig. 2 Molecular structures of (a) 3, (b) the anion component of 5, (c) 6. Structures are depicted with selective symmetry-unique labels, 40\% probability displacement ellipsoids, and hydrogen atoms, minor disorder components, and lattice solvent molecules are omitted for clarity.

nitride, that is consistent with other UNU distances, ${ }^{10}$ the anionic, charge rich nature of this component, since the amide distances are longer than usual for Tren- $\mathrm{U}^{\mathrm{IV}}$ complexes, and possibly a strong trans-influence from the nitride since the amine distances are quite long like in related ThPTh and ThAsTh complexes, ${ }^{16 c, d, e}$ but in contrast to the situation found in a related terminal Tren-uranium(vi)-nitride. ${ }^{11 b}$ In 6 the $\mathrm{U}-\mathrm{N}_{\text {nitride }}$ distances are now inequivalent at 2.081(5) and 2.136(5) $\AA$, and the $\mathrm{U}-\mathrm{N}_{\text {amide }}$ and U- $\mathrm{N}_{\text {amine }}$ distances (av. 2.287(5) and 2.649(5) ̊) are now shorter than in $\mathbf{5}$, presumably reflecting the neutral formulation of 6 and a reduced nitride trans-influence since the $\mathrm{N}_{\text {nitride }}-\mathrm{U}-$ $\mathrm{N}_{\mathrm{amine}}$ angles are now $\sim 159^{\circ}$.

\section{Thorium-azide reductions and characterisation of imido products}

The reduction of $\mathbf{4}$, in contrast to $\mathbf{3}$, gives two distinct products, in addition to $\mathrm{N}_{2}$ and $\mathrm{KN}_{3}$, that are exclusive to the solvent media, Scheme $2 .{ }^{18}$ When aromatic solvents (benzene, toluene) are used instead of securing $\left[\left\{\operatorname{Th}\left(\operatorname{Tren}^{\mathrm{DMBS}}\right)\right\}_{2}(\mu-\mathrm{N})\right][\mathrm{K}]$ the parent imido $\left[\left\{\mathrm{Th}\left(\operatorname{Tren}^{\mathrm{DMBS}}\right)\right\}_{2}(\mu-\mathrm{NH})\right](7)$ is isolated in $52 \%$ crystalline yield. When ethereal solvents (THF, DME) are used the cyclometallated tuck-in-tuck-over ${ }^{27}$ parent imido $\left[\left\{\mathrm{Th}\left(\operatorname{Tren}^{\mathrm{DMBS}}\right)\right\} \mathrm{Th}\left(\mathrm{N}\left[\mathrm{CH}_{2} \mathrm{CH}_{2} \mathrm{NSiMe}_{2} \mathrm{Bu}^{t}\right]_{2} \mathrm{CH}_{2} \mathrm{CH}_{2} \mathrm{NSi}\left[\mu-\mathrm{CH}_{2}\right]\right.\right.$ $\left.\left.\left.\mathrm{MeBu}^{t}\right)\right\}(\mu-\mathrm{NH})\right]\left[\mathrm{K}(\mathrm{DME})_{4}\right](8)$ is isolated in $46 \%$ crystalline yield. The ${ }^{1} \mathrm{H}$ NMR spectrum of 7 reveals a resonance at $5.55 \mathrm{ppm}$ that corresponds to one $\mathrm{N}-\mathrm{H}$ proton; this resonance disappears when the reaction is conducted in $\mathrm{D}_{8}$-toluene, suggesting the source of $\mathrm{H}$ is aromatic solvent with $\mathrm{K}-\mathrm{C}_{6} \mathrm{H}_{5} /-\mathrm{CH}_{2} \mathrm{Ph}$ as byproducts. In-line with this, 7 does not react with benzyl potassium. The presence of the $\mathrm{N}-\mathrm{H}$ group is confirmed by a broad absorption at $3390 \mathrm{~cm}^{-1}$ in the ATR-IR spectrum of 7 . The ${ }^{1} \mathrm{H}$ NMR spectrum of $\mathbf{8}$ is now more complicated due to the desymmetrisation of one of the Tren ${ }^{\text {DMBS }}$ ligands, but the $\mathrm{N}-\mathrm{H}$ proton resonance can be observed at $5.39 \mathrm{ppm}$.
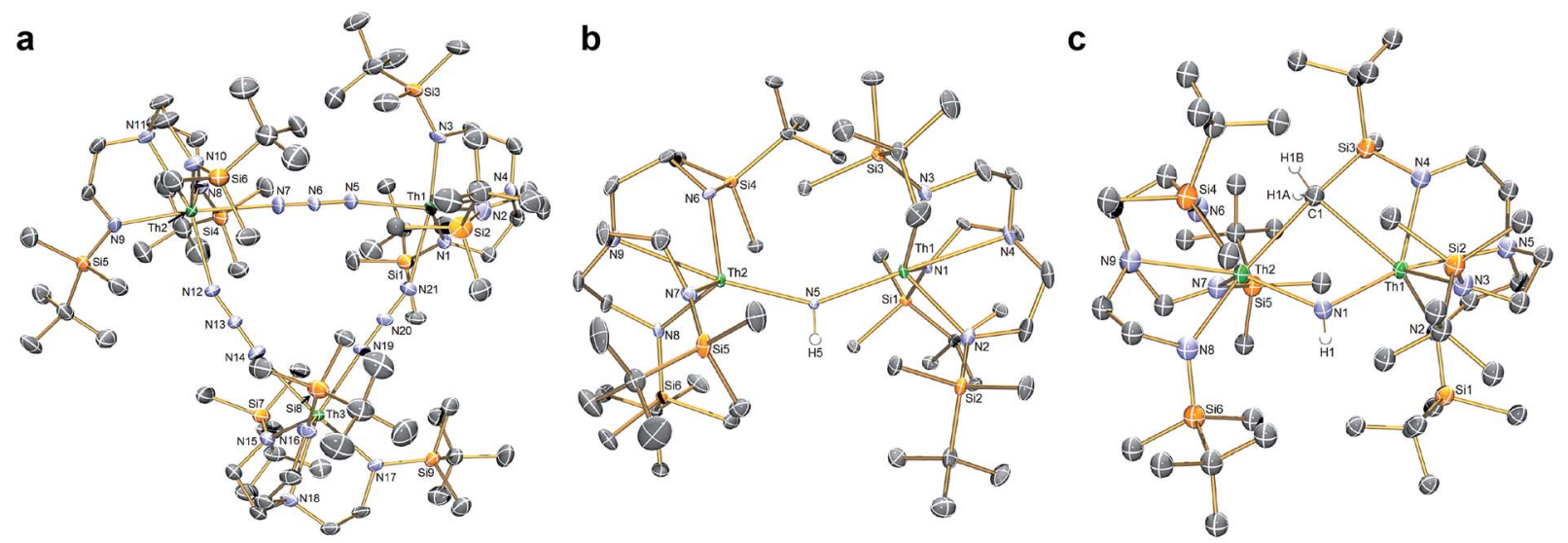

Fig. 3 Molecular structures of (a) 4, (b) 7, (c) the anion component of 8 . Structures are depicted with selective labels, $40 \%$ probability displacement ellipsoids and hydrogen atoms (except $\mathrm{N}-\mathrm{H}$ and $\mathrm{H}_{2} \mathrm{CSi}$ ), minor disorder components, and lattice solvent molecules are omitted for clarity. 


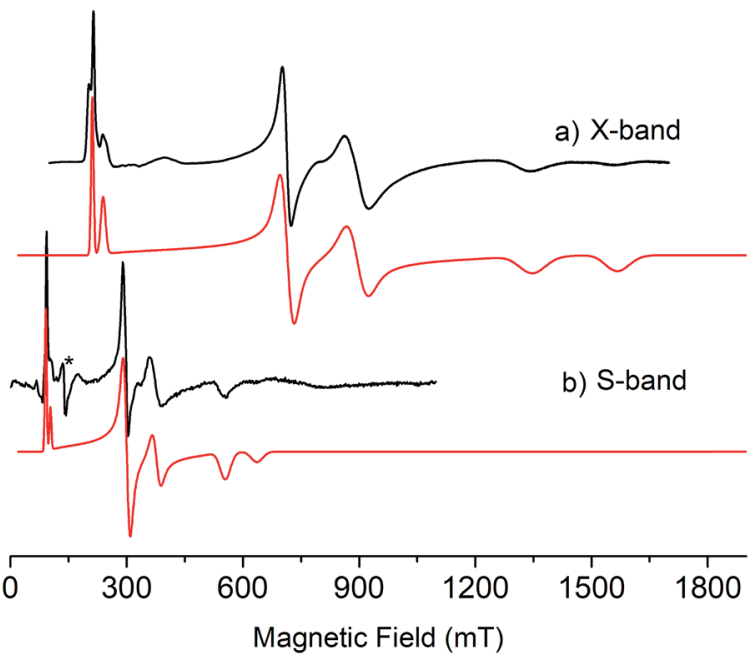

Fig. 4 (a) X-band (9.39 GHz) and (b) S-band (3.87 GHz) EPR spectra of polycrystalline samples of 6 at $5 \mathrm{~K}$. Black lines are experimental data and red lines are simulations. * = cavity signal.

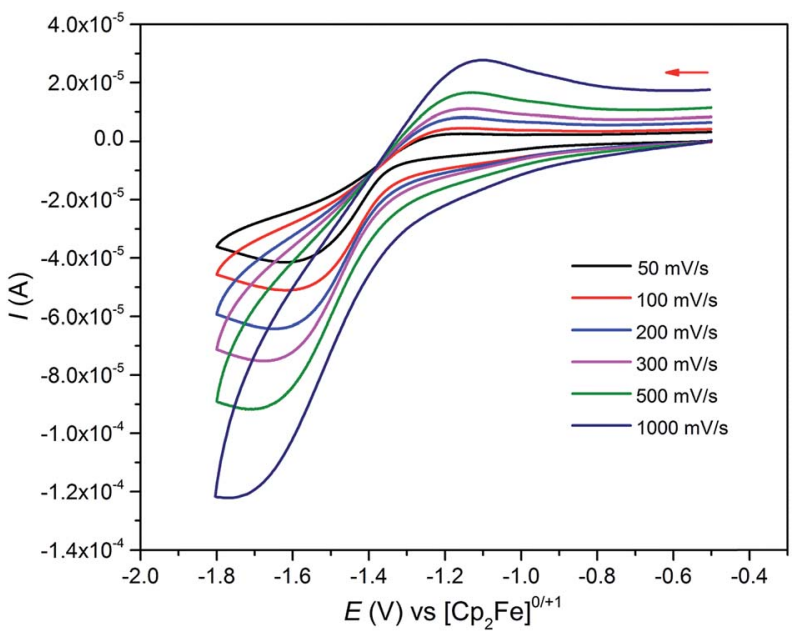

Fig. 5 Cyclic voltammogram of $0.1 \mathrm{M} 6$ in THF at selected sweep rates $\left(0.5 \mathrm{M}\left[\mathrm{N}\left({ }^{n} \mathrm{Bu}\right)_{4}\right]\left[\mathrm{BAr}{ }_{4}\right]\right.$ supporting electrolyte) $v s$. $\left[\mathrm{Fe}(\mathrm{Cp})_{2}\right]^{+/ 0}$ showing a single irreversible redox process. Test solutions of 5 or 6 in THF with $\left[\mathrm{N}\left({ }^{n} \mathrm{Bu}\right)_{4}\right]\left[\mathrm{BAr}_{4}\right]$ under identical conditions show no evidence of stability issues.

The molecular structures of 7 and 8 were determined, Fig. $3 \mathrm{~b}$ and c. In 7 the $\mathrm{Th}-\mathrm{N}_{\text {imido }}-\mathrm{Th}$ angle is $145.96(19)^{\circ}$ and the imido adopts a trigonal planar geometry in contrast to $\mathrm{ThP}(\mathrm{H}) \mathrm{Th}$ and ThAs(H)Th linkages ${ }^{16 c, d}$ that are T-shaped reflecting a $\mathrm{sp}^{2}-\mathrm{NH}$ dianion but p-orbital-dominated bonding of $\mathrm{PH}$ and AsH dianions. The Th- $\mathrm{N}_{\text {imido }}$ distances of 2.331(4) and 2.312(4) $\AA$ are similar to the $\mathrm{Th}-\mathrm{N}_{\text {amide }}$ distances $(\sim 2.330 \AA)$ and $\sim 0.3 \AA$ longer than $\mathrm{Th}=\mathrm{NR}$ terminal imido bonds. ${ }^{13}$ In 8 the $\mathrm{Th}-\mathrm{N}_{\text {imido }}-\mathrm{Th}$ angle is $120.9(7)^{\circ}$, reflecting the presence of the tuck-in-tuckover cyclometallate enforcing a constrained $\mathrm{C}-\mathrm{Th}-\mathrm{N}-\mathrm{Th}$ fourmembered ring. Despite this, the $\mathrm{Th}-\mathrm{N}_{\text {imido }}$ distances of 2.309(15) and 2.264(15) ^ are essentially the same as those in 7 . The Th-C distances of 2.88(2) and 2.78(2) $\AA$ are long, as observed in other Th-Tren ${ }^{\text {DMBS }}$ cyclometallates. ${ }^{28}$ a)

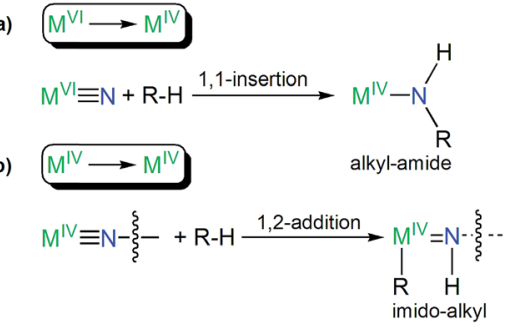

Fig. 6 Systematic types of emerging reactivity patterns of actinidenitrides suggested by this work and ref. $6 b, 10 i$ and $11 b$. (a) $\mathrm{C}-\mathrm{H}$ activation of a $\mathrm{R}-\mathrm{H}$ bond by a metal(vi)-nitride produces a metal(IV)-alkylamide by 1,1-insertion. (b) $\mathrm{C}-\mathrm{H}$ activation of a $\mathrm{R}-\mathrm{H}$ bond by a terminal or bridging metal(IV)-nitride produces a bridging or terminal metal(IV)imido-alkyl by 1,2-addition; the $\mathrm{R}$ group can be coordinated to the metal(Iv) ion or be eliminated with a group 1 metal.
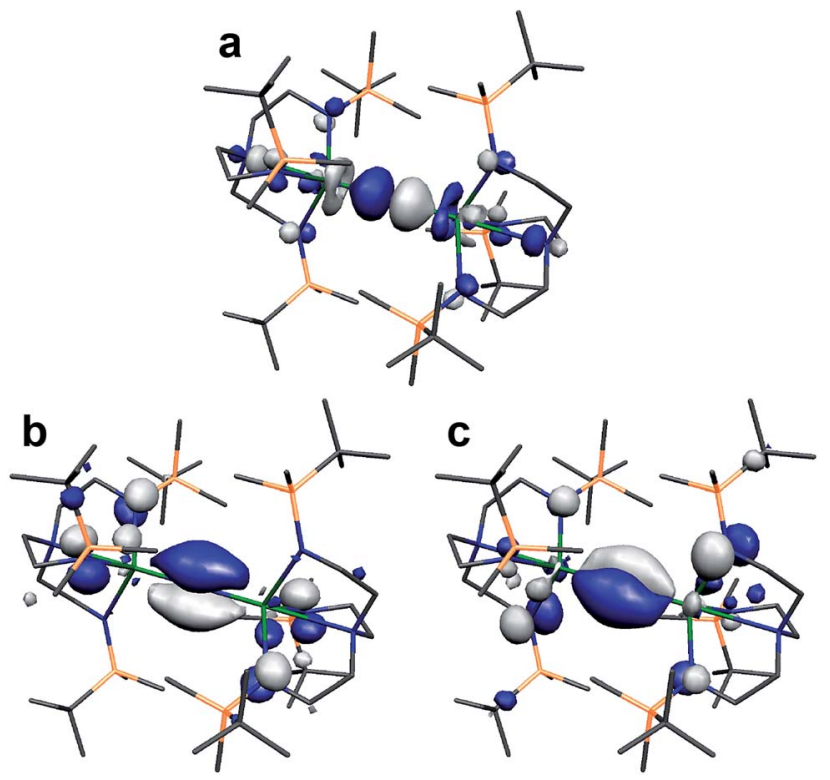

Fig. 7 Kohn Sham molecular orbital representations of the principal frontier orbitals of $9^{-}$with hydrogen atoms omitted for clarity. (a) HOMO (365a, -1.884 eV); (b) HOMO-7 (358a, -2.598 eV); (c) HOMO-8 (357a, $-2.599 \mathrm{eV})$. The computed thorium-nitride distances are 2.1373 and $2.1373 \AA$ and the computed Th- $\mathrm{N}_{\text {nitride }}$-Th angle is $180^{\circ}$.

\section{Discussion of the contrasting nature of uranium- and thorium-nitride reactivities}

The formation and isolation of $\mathbf{5}$ and $\mathbf{6}$, especially the latter under photolytic conditions, is significant because photolysis of terminal uranium(vi)-nitrides ${ }^{10 i, 11 b}$ and a uranium(Iv)-nitride generated transiently by reduction ${ }^{6 b}$ have all resulted in $\mathrm{C}-\mathrm{H}$ activation of ancillary ligands to produce alkyl-amides or a parent imido-alkyl, respectively. However, 5 and $\mathbf{6}$ contain quite robust, redox inter-convertible UNU cores, and when $\mathrm{N}_{2}$ is eliminated from 3 the nitride secures stabilisation by two uranium Lewis acid centres rather than instigating $\mathrm{C}-\mathrm{H}$ activation reactions.

Although reduction of $\mathbf{4}$ does not lead to the isolation of dithorium-nitrides, the isolation of $\mathbf{7}$ and $\mathbf{8}$ is instructive. Like $\mathbf{5}$ 
and 6, reduction of an azide precursor, 4, results in the formation of a ThNTh unit, except in both cases this is protonated. For 7 , the potassium from reduction has been exchanged for a proton suggesting that a transient nitride $\left[\left\{\text { Th }\left(\text { Tren }^{\text {DMBS }}\right)\right\}_{2}(\mu-\mathrm{N})\right]^{-}\left(\mathbf{9}^{-}\right)$has $\mathrm{C}-\mathrm{H}$ activated arene solvents, and we note the yield of 7 does not vary when changing the solvent from benzene to toluene. Likewise, in the formation of 8 a $\mu-\mathrm{NH}$ unit forms again, but this time in the absence of deprotonatable arene solvent, and with the potassium cation sequestered by ethereal solvent, the transient nitride has $\mathrm{C}-\mathrm{H}$ activated the Tren $^{\text {DMBS }}$ to form a tuck-in-tuck-over cyclometallate ${ }^{27,28}$ liberating the requisite proton to form the imido group. We deduce that the transient ThNTh unit is highly reactive, certainly as reactive as $\mathrm{Th}-\mathrm{CR}_{3}$ species that also cyclometallate Trenligands due to proximity and entropy effects, ${ }^{28}$ and more reactive than the stable UNU units in 5 and 6. Indeed, DFT calculations $^{\mathbf{1 8}}$ on $\left[\left\{\mathrm{U}\left(\text { Tren }^{\mathrm{DMBS}}\right)\right\}_{2}(\mu-\mathrm{N})\right]^{-}\left(\mathbf{5}^{-}\right)$and $\mathbf{9}^{-}$suggest that the latter contains more polar and ionic metal-nitride linkages, but importantly the frontier molecular orbitals that principally comprise the ThNTh bonding interactions in $\mathbf{9}^{-}$are destabilised by $\sim 1.1(\sigma)$ and $\sim 0.4(\pi)$ eV compared to the corresponding UNU orbitals of $5^{-}$. This results in a more basic, effectively superbasic, nucleophilic nitride in $\mathbf{9}^{-}$, as experimentally inferred by the isolation of 5 versus 7 and 8, and shown computationally where the anion of $\mathbf{8}$ is found to be $19.8 \mathrm{kcal} \mathrm{mol}^{-1}$ more stable than $\mathbf{9}^{-}$ and formed via a transition state with an experimentally accessible barrier of $16.4 \mathrm{kcal} \mathrm{mol}^{-1} \cdot{ }^{18}$

The formation of $\mathbf{8}$ parallels the reactivity of a transiently formed uranium(Iv)-nitride that undergoes ligand $\mathrm{C}-\mathrm{H}$ activation to give a cyclometallated (alkyl) ligand and a uranium(Iv) parent imido functionality by 1,2 -addition, ${ }^{6 \boldsymbol{b}}$ since the alternative of 1,1-insertion to give an alkyl-amide as observed for uranium(vI)-nitrides ${ }^{\mathbf{1 0 i , 1 1 b}}$ would, formally, implicate the likely very unfavourable formation of sub-valent thorium ions. This suggests that there may be a systematic pattern of $\mathrm{C}-\mathrm{H}$ activation reactions for $\mathrm{M}^{\mathrm{VI}}$ vs. $\mathrm{M}^{\mathrm{IV}}$ ions in this context generally, Fig. 6.

Lastly, we note that the $\sigma$-bonding component of the $\mathrm{U}^{\mathrm{IV}} \mathrm{NU}^{\mathrm{IV}}$ and $\operatorname{Th}^{\mathrm{IV}} \mathrm{NTh}^{\mathrm{IV}}\left(\mathbf{9}^{-}\right.$is depicted in Fig. 7$)$ bonds reported here are higher in energy than the two $\pi$-contributions. ${ }^{18}$ This scenario is usually only observed in terminal uranium nitrides and uranyl with short UN and UO bonds. ${ }^{\mathbf{9}, 11}$ Why this is the case here, and whether this is related to the formation of $\mathbf{7}$ and $\mathbf{8}$, is currently unclear and work is on-going to rationalise this observation.

\section{Conclusions}

In conclusion, the synthesis of two uranium- and thorium-azide complexes has provided rare examples of actinide molecular square and triangle complexes. We have prepared two diuranium-nitride complexes in different charge states; these UNU complexes are quite robust, and do not engage in $\mathrm{C}-\mathrm{H}$ activation chemistry, even under photolytic conditions, unlike terminal uranium(Iv/vi)-nitrides. Attempts to prepare a dithorium-nitride complex resulted in the isolation of two parent imido complexes, in-line with the paucity of isolable molecular thorium-nitrides to date. However, the two dithorium-imido products suggest for the first time that reduction of thoriumazides can generate nitrides, and provides evidence that a transient and highly reactive dithorium-nitride is formed, but that this linkage is highly basic and nucleophilic so is capable of activation $\mathrm{C}-\mathrm{H}$ bonds of arene solvent or the supporting Tren $^{\text {DMBS }}$ ligand. The contrasting stabilities of UNU and putative ThNTh units reported here may be related to the general tendency of uranium to engage in more covalent bonding than thorium, on a like-for-like basis. The results here suggest a general pattern of actinide-nitride reactivity where metal(Iv)nitrides, bridging or terminal, activate $\mathrm{C}-\mathrm{H}$ bonds to produce imido-alkyl combinations, whereas metal(vi)-nitrides produce alkyl-amide linkages, which can be related to the range of accessible oxidation states of these ions during reactions. Lastly, computational studies surprisingly reveal a $\sigma>\pi$ energy ordering for the bridging nitride linkages in this study, a phenomenon so far only found in terminal uranium-nitrides and uranyl complexes with very short U-N/-O distances.

\section{Conflicts of interest}

There are no conflicts to declare.

\section{Acknowledgements}

We gratefully acknowledge funding and support from the UK Engineering and Physical Sciences Research Council (grants EP/ K024000/1, EP/M027015/1, and EP/P001386/1), European Research Council (grant CoG612724), Royal Society (grant UF110005), the National EPSRC UK EPR Facility, The Universities of Manchester and Nottingham, and the UK National Nuclear Laboratory. The X-ray crystallographic coordinates for structures reported in this article have been deposited at the Cambridge Crystallographic Data Centre (CCDC), under deposition number CCDC 1868610-1868615. $\dagger$ All other data are available from the corresponding authors upon request.

\section{Notes and references}

1 (a) T. W. Hayton, Dalton Trans., 2010, 39, 1145; (b) T. W. Hayton, Chem. Commun., 2013, 49, 2956; (c) M. B. Jones and A. J. Gaunt, Chem. Rev., 2013, 113, 1137; (d) H. S. La Pierre and K. Meyer, Prog. Inorg. Chem., 2014, 58, 303.

2 S. T. Liddle, Angew. Chem., Int. Ed., 2015, 54, 8604.

3 (a) T. W. Hayton, J. M. Boncella, B. L. Scott, P. D. Palmer, E. R. Batista and P. J. Hay, Science, 2005, 310, 1941; (b) T. W. Hayton, J. M. Boncella, B. L. Scott, E. R. Batista and P. J. Hay, J. Am. Chem. Soc., 2006, 128, 10549; (c) T. W. Hayton, J. M. Boncella, B. L. Scott and E. R. Batista, J. Am. Chem. Soc., 2006, 128, 12622; (d) L. P. Spencer, P. Yang, B. L. Scott, E. R. Batista and J. M. Boncella, J. Am. Chem. Soc., 2008, 130, 2930.

4 (a) N. H. Anderson, S. O. Odoh, Y. Yao, U. J. Williams, B. A. Schaefer, J. J. Kiernick, A. J. Lewis, M. D. Goshert, P. E. Fanwick, E. J. Schelter, J. R. Walensky, L. Gagliardi and S. C. Bart, Nat. Chem., 2014, 6, 919; (b) 
N. H. Anderson, H. Yin, J. J. Kiernicki, P. E. Fanwick, E. J. Schelter and S. C. Bart, Angew. Chem., Int. Ed., 2015, 54, 9386.

5 N. H. Anderson, J. Xie, D. Ray, M. Zeller, L. Gagliardi and S. C. Bart, Nat. Chem., 2017, 9, 850.

6 (a) D. M. King, J. McMaster, F. Tuna, E. J. L. McInnes, W. Lewis, A. J. Blake and S. T. Liddle, J. Am. Chem. Soc., 2014, 136, 5619; (b) K. C. Mullane, H. Ryu, T. Cheisson, L. N. Grant, J. Y. Park, B. C. Manor, P. J. Carroll, M.-H. Baik, D. J. Mindiola and E. J. Schelter, J. Am. Chem. Soc., 2018, 140, 11335.

7 (a) M. Falcone, L. Chatelain and M. Mazzanti, Angew. Chem., Int. Ed., 2016, 55, 4074; (b) M. Falcone, C. E. Kefalidis, R. Scopelliti, L. Maron and M. Mazzanti, Angew. Chem., Int. Ed., 2016, 55, 12290; (c) M. Falcone, L. Chatelain, R. Scopelliti, I. Živković and M. Mazzanti, Nature, 2017, 547, 332; (d) M. Falcone, L. N. Poon, F. Fadaei Tirani and M. Mazzanti, Angew. Chem., Int. Ed., 2018, 57, 3697.

8 (a) W. J. Evans, S. A. Kozimor and J. W. Ziller, J. Am. Chem. Soc., 2003, 125, 14264; (b) N. A. Siladke, K. R. Meihaus, J. W. Ziller, M. Fang, F. Furche, J. R. Long and W. J. Evans, J. Am. Chem. Soc., 2012, 134, 1243.

9 D. M. King and S. T. Liddle, Coord. Chem. Rev., 2014, 266267, 2.

10 (a) I. Korobkov, S. Gambarotta and G. P. A. Yap, Angew. Chem., Int. Ed., 2002, 41, 3433; (b) W. J. Evans, S. A. Kozimor and J. W. Ziller, Science, 2005, 309, 1835; (c) W. J. Evans, K. A. Miller, J. W. Ziller and J. Greaves, Inorg. Chem., 2007, 46, 8008; (d) G. Nocton, J. Pécaut and M. Mazzanti, Angew. Chem., Int. Ed., 2008, 47, 3040; (e) A. R. Fox and C. C. Cummins, J. Am. Chem. Soc., 2009, 131, 5716; (f) A. R. Fox, P. L. Arnold and C. C. Cummins, J. Am. Chem. Soc., 2010, 132, 3250; $(g)$ S. Fortier, G. Wu and T. W. Hayton, J. Am. Chem. Soc., 2010, 132, 6888; (h) T. K. Todorova, L. Gagliardi, J. R. Walensky, K. A. Miller and W. J. Evans, J. Am. Chem. Soc., 2010, 132, 12397; (i) R. K. Thomson, T. Cantat, B. L. Scott, D. E. Morris, E. R. Batista and J. L. Kiplinger, Nat. Chem., 2010, 2, 723; (j) C. Camp, J. Pécaut and M. Mazzanti, J. Am. Chem. Soc., 2013, 135, 12101; (k) N. Tsoureas, A. F. R. Kilpatrick, C. J. Inman and F. G. N. Cloke, Chem. Sci., 2016, 7, 4624.

11 (a) D. M. King, F. Tuna, E. J. L. McInnes, J. McMaster, W. Lewis, A. J. Blake and S. T. Liddle, Science, 2012, 337, 717; (b) D. M. King, F. Tuna, E. J. L. McInnes, J. McMaster, W. Lewis, A. J. Blake and S. T. Liddle, Nat. Chem., 2013, 5, 482; (c) P. A. Cleaves, D. M. King, C. E. Kefalidis, L. Maron, F. Tuna, E. J. L. McInnes, J. McMaster, W. Lewis, A. J. Blake and S. T. Liddle, Angew. Chem., Int. Ed., 2014, 53, 10412; (d) D. M. King, P. A. Cleaves, A. J. Wooles, B. M. Gardner, N. F. Chilton, F. Tuna, W. Lewis, E. J. L. McInnes and S. T. Liddle, Nat. Commun., 2016, 7, 13773; (e) P. A. Cleaves, C. E. Kefalidis, B. M. Gardner, F. Tuna, E. J. L. McInnes, W. Lewis, L. Maron and S. T. Liddle, Chem.-Eur. J., 2017, 23, 2950.

12 (a) N. Kaltsoyannis, Inorg. Chem., 2013, 52, 3407; (b) M. L. Neidig, D. L. Clark and R. L. Martin, Coord. Chem. Rev., 2014, 257, 394.
13 (a) A. Haskel, T. Straub and M. S. Eisen, Organometallics, 1996, 15, 3773; (b) W. Ren, G. Zi, D.-C. Fang and M. D. Walter, J. Am. Chem. Soc., 2011, 133, 13183; (c) W. Ren, G. Zi and M. D. Walter, Organometallics, 2012, 31, 672; (d) N. L. Bell, L. Maron and P. L. Arnold, J. Am. Chem. Soc., 2015, 137, 10492; (e) M. E. Garner, S. Hohloch, L. Maron and J. Arnold, Organometallics, 2016, 35, 2915.

14 (a) G. P. Kushto, P. F. Souter and L. Andrews, J. Chem. Phys., 1998, 108, 7121; (b) M. Zhou and L. Andrews, J. Chem. Phys., 1999, 111, 11044; (c) X. Wang and L. Andrews, Dalton Trans., 2009, 9260.

15 I. Korobkov, S. Gambarotta and G. P. A. Yap, Angew. Chem., Int. Ed., 2003, 42, 4958.

16 (a) B. M. Gardner, G. Balázs, M. Scheer, F. Tuna, E. J. L. McInnes, J. McMaster, W. Lewis, A. J. Blake and S. T. Liddle, Angew. Chem., Int. Ed., 2014, 53, 4484; (b) B. M. Gardner, G. Balázs, M. Scheer, F. Tuna, E. J. L. McInnes, J. McMaster, W. Lewis, A. J. Blake and S. T. Liddle, Nat. Chem., 2015, 7, 582; (c) E. P. Wildman, G. Balázs, A. J. Wooles, M. Scheer and S. T. Liddle, Nat. Commun., 2016, 7, 12884; (d) E. P. Wildman, G. Balázs, A. J. Wooles, M. Scheer and S. T. Liddle, Nat. Commun., 2017, 8, 14769; (e) T. M. Rookes, B. M. Gardner, G. Balázs, M. Gregson, F. Tuna, A. J. Wooles, M. Scheer and S. T. Liddle, Angew. Chem., Int. Ed., 2017, 56, 10495.

17 P. Roussel, N. W. Alcock, R. Boaretto, A. J. Kingsley, I. J. Munslow, C. J. Sanders and P. Scott, Inorg. Chem., 1999, 38, 3651.

18 See the ESI $\dagger$ for further details.

19 (a) N. A. Budantseva, G. B. Andreev, A. M. Fedoseev and M. Y. Antipin, Russ. J. Coord. Chem., 2003, 29, 265; (b) I. Castro-Rodriguez and K. Meyer, J. Am. Chem. Soc., 2005, 127, 11242; (c) S. Fortier, G. Wu and T. W. Hayton, Dalton Trans., 2010, 39, 352; (d) O. Bénaud, J.-C. Berthet, P. Thuéry and M. Ephritikhine, Inorg. Chem., 2011, 50, 12204; (e) W. Ren, E. Zhou, B. Fang, G. Hou, G. Zi, D.-C. Fang and M. D. Walter, Angew. Chem., Int. Ed., 2014, 53, 11310; ( $f$ ) M. J. Monreal, L. A. Seaman, G. S. Goff, R. Michalczyk, D. E. Morris, B. L. Scott and J. L. Kiplinger, Angew. Chem., Int. Ed., 2016, 55, 3631.

20 (a) I. Castro-Rodríguez and K. Meyer, Chem. Commun., 2006, 1353; (b) D. R. Kindra and W. J. Evans, Chem. Rev., 2014, 114, 8865.

21 P. H. Dinolfo, S.-S. Sun and J. T. Hupp, Encyclopedia of Supramolecular Chemistry, ed. J. L. Atwood and J. W. Steed, CRC Press, 2004, p. 395.

22 (a) J. M. Manriquez, P. J. Fagan, T. J. Marks, S. H. Vollmer, C. S. Day and V. W. Day, J. Am. Chem. Soc., 1979, 101, 5075; (b) P. C. Leverd, T. Arliguie, M. Ephritikhine, M. Nierlich, M. Lance and J. Vigner, New J. Chem., 1993, 17, 769; (c) D. L. Clark, J. C. Gordon, J. C. Huffman, J. G. Watkin and B. D. Zwick, New J. Chem., 1995, 19, 495; (d) J. L. Kiplinger, J. A. Pool, E. J. Schelter, J. D. Thompson, B. L. Scott and D. E. Morris, Angew. Chem., Int. Ed., 2006, 45, 2036; (e) C. P. Larch, F. G. N. Cloke and P. B. Hitchcock, Chem. Commun., 2008, 82; (f) M. J. Monreal, S. I. Khan, 
J. L. Kiplinger and P. L. Diaconescu, Chem. Commun., 2011, 47, 9119.

23 D. P. Halter, H. S. La Pierre, F. W. Heinemann and K. Meyer, Inorg. Chem., 2014, 53, 8418.

$24 \mathrm{U}^{\mathrm{IV}}-\mathrm{U}^{\mathrm{IV}}$ magnetic exchange coupling is rare: (a) J. D. Rinehart, T. D. Harris, S. A. Kozimor, B. M. Bartlett and J. R. Long, Inorg. Chem., 2009, 48, 3382; (b) B. S. Newell, A. K. Rappé and M. P. Shores, Inorg. Chem., 2010, 49, 1595; (c) O. P. Lam, F. W. Heinemann and K. Meyer, Chem. Sci., 2011, 2, 1538; (d) B. M. Gardner, J. C. Stewart, A. L. Davis, J. McMaster, W. Lewis, A. J. Blake and S. T. Liddle, Proc. Natl. Acad. Sci. U. S. A., 2012, 109,
9265; (e) B. M. Gardner, D. M. King, F. Tuna, A. J. Wooles, N. F. Chilton and S. T. Liddle, Chem. Sci., 2017, 8, 6207.

25 R. K. Rosen, R. A. Andersen and N. M. Edelstein, J. Am. Chem. Soc., 1990, 112, 4588.

26 A. Formanuik, A.-M. Ariciu, F. Ortu, R. Beekmeyer, A. Kerridge, F. Tuna, E. J. L. McInnes and D. P. Mills, Nat. Chem., 2017, 9, 578.

27 B. M. Gardner, J. McMaster, W. Lewis, A. J. Blake and S. T. Liddle, J. Am. Chem. Soc., 2009, 131, 10388.

28 B. M. Gardner, W. Lewis, A. J. Blake and S. T. Liddle, Organometallics, 2015, 34, 2386. 